\title{
LEVEL OF SEISMIC PROTECTION IN DIFFERENT EDITTIONS OF THE EGYPTIAN CODE OF LOADS
}

\author{
Waleed Abo El-Wafa Mohamed \\ Lecturer, Civil Engineering Department, Faculty of Engineering, Assiut \\ University, Assiut, Egypt.
}

(Received August 6, 2009 Accepted August 24, 2009).

The last edition of the Egyptian Code of Loads (ECOL) was released by the end of year 2008. The seismic provisions in this edition are almost completely different compared with those in the 1993 edition while some specific changes are presented relative to the 2003 edition. The major significant changes in the seismic provisions revealed in the different editions are reviewed. The effect of the variation in these provisions between the different editions of the ECOL on the level of seismic protection presented by the code calculated base shear is analyzed and discussed. The analyzed provisions include seismic zones and mapping, period equations, soil site conditions, building importance factor, and ductility level. These provisions are applied to two types of structures which are moment resisting frames (MRF) and dual system consists of shear wall-moment resisting frames ( $S W-M R F)$. The considered height of buildings covers almost all code permitted range of heights. It is found that the provisions in the 1993 edition yield base shear much less than the values obtained using 2008 edition especially for low to medium height buildings located in medium and high seismic zones.

KEYWORDS: Seismic codes, ECOL, equivalent static load method, seismic provisions.

\section{INTRODUCTION}

The first edition of the ECOL [1] containing seismic provisions was issued in 1993. These provisions were highly influenced by concepts presented by the Uniform Building Code $U B C-85$ [2], however, some provisions in the $U B C$ - 85 were modified to suit the seismicity nature and soil types in Egypt. In this code, the seismic base shear was seen to be a percentage of the total dead load of the structure. This percentage depends on the site seismicity, soil condition, the utilization importance, fundamental period and the type of seismic force resisting system. A seismic map which classifies Egypt into three different zones was provided. In this code, the equivalent static load (ESL) method was the dominant design method which could be used for structures having uniform lateral load resisting systems up to $100 \mathrm{~m}$. Otherwise, modal spectrum response, under some restrictions, and time history analysis are mandatory required methods. However, the results obtained using the modal analysis method were limited to $80 \%$ of the base shear calculated using the ESL method. In this edition, no design response spectrum neither provisions for the selected ground excitation is presented.

The second edition of this code of loads, 2003 ECOL [3], was issued in year 2003. The seismic loads on buildings included in this code were basically relying on 
the Eurocode-8 [4], January 2001 edition. The seismic provisions in this edition had experienced major significant changes related the previous edition. Egypt had been divided into five seismic regions according to design ground acceleration $\left(a_{g}\right)$ which ranges from $0.1 \mathrm{~g}$ to $0.25 \mathrm{~g}$. Two types of elastic response spectrum are provided, type 1 which is valid for all regions and type 2 which is valid to coastal cities along the Mediterranean sea. Mainly, this edition adopted the concept of multi modal response spectrum (multi MRS) as the basic design method which is valid to all types of structures. ESL, (called in this code simplified MRS) method is still applicable but with higher restrictions. Using time history analysis THA is also permitted but with certain conditions. Many new provisions related to analysis methods, structural regularity, combination of earthquake action components, nonstructural elements and safety verification are presented in that edition.

Finally, a modified version of this code, under same title, is revealed in September 2008 [5]. The seismic provisions in this code are almost, except some specific significant changes, similar to the provisions presented by the 2003 ECOL edition. These changes include appending a new seismic zone along with changing the seismic intensity of some towns. Some changes are also applied to the structural modeling, safety verification and period equations.

The continuous evolutions in seismic provisions revealed in national building codes always triggered the researchers enthusiasm to pursue and investigate the different provisions of such seismic codes. The effort of the researchers has been paid in many code related aspects. Examples, include seismic zone maps and code elastic response spectrum as [6] and [7] concerned with Eurocode-8 and National building code of Canada $N B C C$, respectively. The major significant changes in different national code editions were, sometimes, overviewed [8], [9]. The seismic provisions in previous ECOL editions have also attained the researchers attention dealing with specific items as suggested code fundamental period equations [10], [11], the performance and ductility level of reinforced concrete buildings [12] and nonstructural elements [13], [14].

The continuous evolutions in the Egyptian seismic provisions appeared in the different editions of the ECOL motive such code related studies to be urgently accomplished to assess the impact of their variations on the seismic protection level they introduce. Thus, the primary motivation for the present study is precisely to overview and discuss the significant changes of the seismic provisions in the successive series of the ECOL. This is to be done along with carrying out an analytical investigation to evaluate the impact of variations in some significant seismic provisions as seismic zones and mapping, period equations, soil site conditions, building importance factor, and ductility level. Different building types as moment resisting frames (MRF) and shear wall-moment resisting frames (SW-MRF) designed using the equivalent static load method are used in this investigation. The investigated buildings have variable heights to represent wide range of building height categories beginning from as low rise buildings with height of $7.5 \mathrm{~m}$ and increasing the building height to the code maximum permitted height so that the simple modal response spectrum method is to be valid. Thus, the investigated buildings are with heights up to $31.5 \mathrm{~m}$ in case of MRF and $52.5 \mathrm{~m}$ in case of SW-MRF buildings. 


\section{SUMMARY OF MAJOR SEISMIC PROVISION CHANGES}

In the following section, the major changes that have been applied to the seismic provisions in the different ECOL editions released from year 1993 to year 2008 are summarized, overviewed and discussed. For the purpose of easier comprehending of these changes, the base shear formulas and related parameters of the editions with major changes, 1993 and 2008 editions, are illustrated in Table $\mathbf{1}$ followed by a brief discussion.

Table 1: Base shear formulas in the 1993 and 2008 ECOL editions

\begin{tabular}{|l|l|l|}
\hline Parameter & \multicolumn{1}{|c|}{$1993 \mathrm{ECOL}$} & \multicolumn{1}{|c|}{$2008 \mathrm{ECOL}$} \\
\hline Equivalent static load & $V=Z . I . K . C . S . W$ & $\begin{array}{l}F_{b}=S_{d}\left(T_{I}\right) \lambda W / g ; S_{d}(T) \text { is the design } \\
\text { response spectrum which is related to } \\
a_{g}, \gamma_{I}, S, \eta, R, T \text { and spectrum periods. }\end{array}$ \\
\hline Seismic hazard parameter & $Z=0.1,0.2,0.3$ & $a_{g}=(0.1,0.125,0.15,0.2,0.25$ and 0.3$) \mathrm{g}$ \\
\hline Importance factor & $I=1$ or 1.25 & $\gamma_{I}=0.8,1,1.2$ and 1.4 \\
\hline Structural resisting system & $0.67 \leq K \leq 1.33$ & $2 \leq R \leq 7$ \\
\hline Site response factor & $S=1 ., 1.15$ or & $S$ is related to soil class and spectrum type \\
\hline Period effect & 1.3 & $S_{d}\left(T_{I}\right)$ is related to period $\left(T_{I}\right)$ \\
\hline Correction factor & $C=1 / 15 \sqrt{T}$ & $\lambda=0.85$ or 1.0 \\
\hline Damping correction & - & $0.95 \leq \eta \leq 1.2$ \\
\hline
\end{tabular}

The major evolution between 1993 edition and the later editions was remarked by the new adoption of the aspect of response spectrum acceleration anchored to PGA. The treatment of base shear formulation in the two versions of 2003 and 2008 ECOL is similar except the existence of importance factor $\gamma_{I}$ either in response spectrum or in base shear equation which yields final identical base shear. It is worth to mention here that the base shear obtained from 2003 and 2008 editions, rather than the 1993 edition, is ultimate load that when used in the elastic theory it must be reduced by a factor of 1.4 or 1.28 for 2008 and 2003 editions, respectively.

\subsection{Seismic Zones and Design Response Spectra}

The 1993 ECOL provided a seismic map which classifies Egypt to three different seismic zones, arranged from lower to higher seismicity, as zones I, II and III, respectively. A seismic intensity factor is identified for each zone, this factor takes the value $0.1,0.2$ and 0.3 for zone I, II and III, respectively.

The map was changed in the 2003 ECOL edition. An elastic response spectrum acceleration was constructed by anchoring a spectral shape defined for each site class to the design peak ground acceleration (PGA). The site classification in the new map was remarked by different five zones related to PGA acceleration of values range between $0.1 \mathrm{~g}$ to $0.25 \mathrm{~g}$. Two types of response spectrum were provided, type 1 which is valid for all regions in the country and type 2 which is valid only for coastal cities along the Mediterranean sea. It is worth to mention here that type 1 spectrum in the 
2003 ECOL is type 2 spectrum in Eurocode- 8 which was recommended by the later code for regions only affected by earthquakes of magnitude $\mathrm{M}_{\mathrm{s}}<5.5$. The $2003 E C O L$ type 2 spectrum is type 1 spectrum in Eurocode- 8 which, the later code, recommended for regions affected by larger events. Fig. 1 [15] compares type 2 spectral shape of Eurocode-8 with median spectral ordinates for earthquakes of different magnitudes. The figure illustrates that the spectral shape will approximate that expected for a particular earthquake magnitude but then tend to over-and under-estimate the longer period ordinates for smaller and larger events, respectively. Fig. 2 illustrates the two types of elastic spectrum for the different specified soil conditions, noting that the vertical axis is normalized to the PGA .



Fig. 1: Eurocode- 8 type 2 spectrum versus median earthquake spectrum (rock soil)

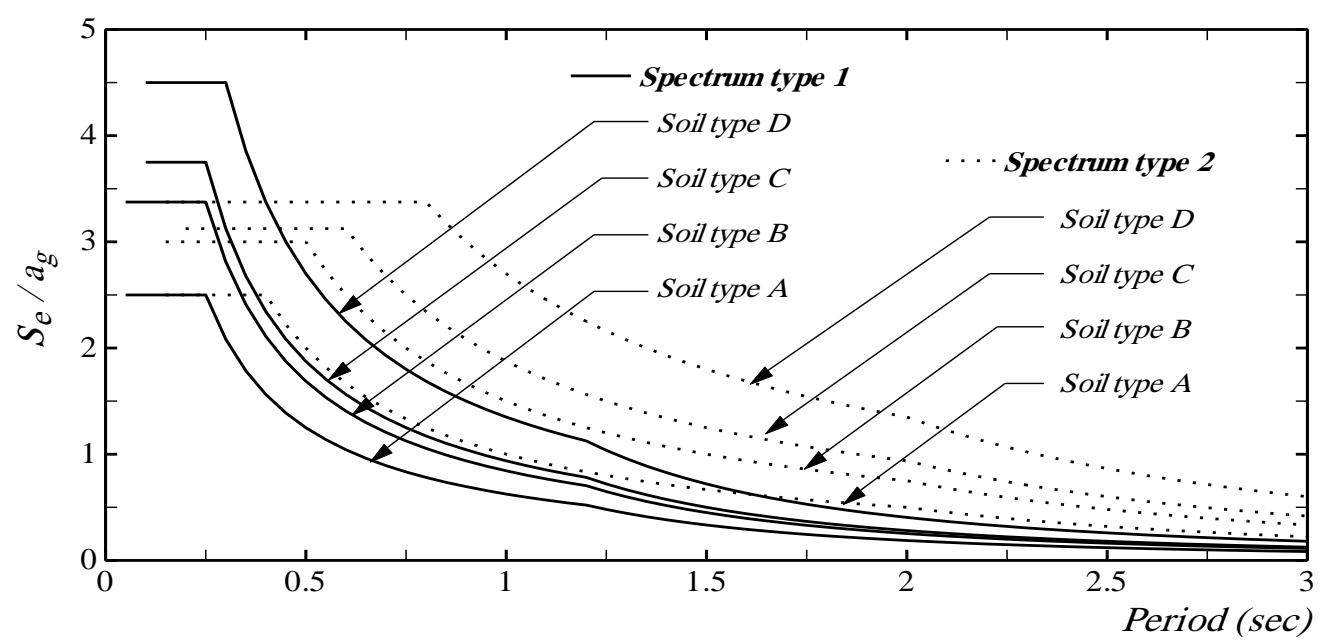

Fig. 2: The ECOL types 1 and 2 response spectrum for different site conditions

The 2008 ECOL continued using the same spectrum types while an additional zone was appended, zone 5 is divided into two classes which are zone $5 \mathrm{a}$ with $a_{g}$ equals $0.25 \mathrm{~g}$ and zone $5 \mathrm{~b}$ with $a_{g}$ equals $0.30 \mathrm{~g}$. 
Many cities had experienced changes in the seismic zone intensities from 1993 ECOL to 2003 ECOL. Examples of governorates that witnessed downgrading in its seismic intensity, relative to the code index, include most of the cities in the upper Egypt and some cities along the Mediterranean sea. However, minor changes could be observed between the 2003 and 2008 editions, this change is remarked by increasing the intensity of two cities, Taba and Shidwan island, from $a_{g}=0.25 \mathrm{~g}$ to $0.30 \mathrm{~g}$.

\subsection{Soil Conditions}

The amplification of soil condition at a site can significantly affect the seismic hazard. In 1993 ECOL edition the effect of soil was related directly to the base shear equation through the factor $S$. This factor was defined by a largely qualitative description of the soil. Three soil profiles were arranged in order of increasing flexibility from rock to alluvium soil, the corresponding values of $S$ are shown in Table 1. The construction of elastic spectrum in the 2003 ECOL edition is related to the soil conditions. In this edition, soil was classified into four ground types A, B, C and D, arranged from rock to loose soils. In this edition of code, soil is more precisely described using the undrained shear strength of soil, standard penetration test blow-count and shear wave velocity. However, it is permitted for low and normal importance buildings and those located in zones with low seismicity to use soil classification C. Otherwise, soil experiments should be carried out.

\subsection{Period Determination}

The fundamental period $T$ is an important design parameter that plays a significant role in the computation of design base shear either directly as the case in 1993 ECOL or determine the values needed to construct the spectral response acceleration for other editions. The value of $T$ should not be overestimated as this results in an underestimation of the seismic design forces.

In addition to the possible available methods, two equations were permitted by the 1993 ECOL to calculate the fundamental period. The first for MRF buildings which related $T$ to the number of floors $(N)$ as:

$T=0.1 N$

The second equation is adopted for other building types as:

$T=\frac{0.09 H}{\sqrt{B}}$

where $H$ is the total height of the building and $B$ is the maximum base dimensions of the building along the considered direction of seismic force.

The 2003 ECOL edition completely eliminated these two equations. Instead, it related the period of different types of structures directly to the building height as

$T=C_{t} H^{3 / 4}$

in which, $C_{t}=0.085$ or 0.075 or 0.05 for steel MRF buildings, concrete MRF or braced steel MRF buildings and any other building type, respectively. 
Alternatively, the value of $C_{t}$ in Eq. 3 for structures with concrete or masonry shear walls may be taken as:

$C_{t}=0.075 / \sqrt{A_{c}}$

with $A_{c}=\sum A_{i}\left(0.2+\left(L_{w i} / H\right)\right)^{2}$

in which;

$A_{c}$ is the combined effective area of shear walls in the first storey.

$A_{i}$ is the effective cross sectional area of shear walls in the first storey.

$L_{w i}$ is the length of shear wall $i$ in the first storey.

Other methods were also allowed. It was found [10] that the dominator $C_{t}$ when calculated from Eqs. $\mathbf{4}$ and $\mathbf{5}$ results in drastic variation in the results due to changing the ratio or number of shear walls and also this equation extremely overestimates the period value. It was also found that the value of $T$ obtained from computer modal analysis of bare frames without taking the effect of infill walls is overestimated.

The 2008 ECOL edition continue to use Eq. 3 while it eliminated the second alternative used to calculate $C_{t}$ from Eqs. 4 and 5. Also, this edition allowed the use of computer modal analysis to get $T$ but the obtained value is now restricted not to exceed 1.2 of the value calculated from Eq. 3 .

\subsection{Response Reduction Factor}

Seismic forces are reduced when structural response goes into the inelastic range. This is an important feature in enabling structures to resist strong earthquake shaking, provided of course that the structure has the capacity to deform inelastically through several load reversals without a significant loss of strength. The 2003 and 2008 ECOL incorporates this recognition by including a force modification factor $R$ used in the construction of the design response spectrum. Thus, the structure could be designed according to seismic loads less than that is specified by the elastic response spectrum due to incorporating this factor. This factor is varying from 2.0 to 7.0 according to both the lateral load resisting system and the required degree of ductility. For MRF building this factor takes the values of 5.0 and 7.0 for limited and sufficient ductility, respectively, while for dual SW-MRF buildings it is either 5.0 or 6.0 for the prementioned ductility levels, respectively.

The corresponding utilized factor in the 1993 edition is called structural system factor $(K)$ and is applied directly to base shear equation. A reference value of 1.0 is specified for dual system while a reduction in base shear of 0.8 and 0.67 could be done for unductile and ductile MRF buildings, respectively.

\subsection{Importance Factor}

The seismic protection level anticipated for a structure always depends on the degree of importance it carry. All versions of ECOL uses a basic value of 1.0 for ordinary structures. The 1993 edition specifies only another value of 1.25 for buildings whose integrity during earthquakes is of vital importance for civil protection. The 2003 or 
2008 editions still keep the value of 1.0 for ordinary buildings while increasing the value assigned to vital structures to 1.4. An innovated value of 1.2 is assigned to buildings whose their seismic resistance during earthquakes is of importance in view of the consequences associated with a collapse, e.g. schools, assembly halls, cultural institutions etc. Buildings of minor importance, e.g. agricultural buildings are assigned an importance factor of 0.8 .

\subsection{Weight of Structure}

As the base shear is always related to the weight of the structure, the later is very important to be well identified. The weight of structure to be used in the base shear formulas was the deal load of the structure for buildings with live load less than 500 $\mathrm{Kg} / \mathrm{m}^{2}$ and for structures with higher live loads, half of the live load is to be considered in addition to the dead load. This concept was changed in the 2003 edition. In addition to the dead load a fraction of live load to be considered depending on the type of building. This fraction is 1.0 for silos, water tanks, libraries, garages, etc., and is equal to 0.5 for public buildings as schools, theatres, markets and etc. The 2008 edition continues to use these rules and added a factor of 0.25 for dwellings.

\subsection{Treatment of Irregularity}

The only definition of irregularity in the 1993 ECOL considered that regular structural system as the system at which the vertical construction items extends to the foundation without sudden change in stiffness. The concept of irregularity was more precisely treated in the 2003 or 2008 ECOL editions which have the same provisos. Firstly, the analysis type, whether plan or spatial, and the type of spectrum analysis, whether simplified or multi modal, are determined now according to the regularity of the structure in plan and elevation. Then, detailed provisions are presented to define separately the criteria for regularity in plan and elevation.

\subsection{Modal Spectrum and Dynamic Analysis Requirements}

Equivalent static load method ESL was the dominant method in the1993 ECOL. This edition permitted utilizing this method for regular, in shape and system, structures up to $100 \mathrm{~m}$ height and with height to width ratio not exceed 5.0. No precise definition was applied to shape regularity. Practically, this method was valid to be applicable to most buildings. The multi modal response spectrum method (multi MRS) was applicable for buildings with heights from 100 to $150 \mathrm{~m}$ and with height to width ratio higher than 5. For buildings with higher heights, the dynamic method of analysis should be applied. However, as mentioned before, neither design response spectrum acceleration nor any dynamic requirements was applied. This code edition specifies that the forces obtained from the MRS should be scaled to at least $80 \%$ of the values obtained using ESL method.

The later editions of the ECOL became more stringent with the ESL method, sometimes called in these editions simplified MRS method, that multi MRS and dynamic analysis could play a very prominent role. Same treatment in the 2003 and 2008 editions is observed. In these editions the application of simplified MRS analysis is limited to regular, in plan and elevation, structures with fundamental period equal or less than either $4.0 T_{c}$ or $2.0 \mathrm{sec}$. The value of $T_{c}$ depends on the spectrum type and the 
soil condition. As the values of $T_{c}$ related to spectrum type 1 is either 0.3 for subsoil class D and 0.25 for other soil types, the applicability of this method will be highly restricted to structures having $T$ less than either $1.2 \mathrm{sec}$ or $1.0 \mathrm{sec}$ for the mentioned soil types, respectively. The multi MRS method is valid to be applied to all types of buildings. Conducting multi MRS analysis is now facilitated by introducing the response spectrum accelerations. Time history analysis THA is also permitted for all types of buildings ensuring that the ground motion histories should be compatible with the response spectrum specified by the code in the critical period range. Three seismic records are minimum required, and hence the maximum response of them is considered, or seven accelograms are required to be used to consider the average of the resulting forces. Unlike the previous 1993 edition, and many international codes as will be discussed later, the forces obtained from the multi MRS analysis are not limited or scaled to those obtained using the simplified MRS method. Otherwise, the response obtained from the THA is required not to be less than $80 \%$ of those obtained using multi MRS analysis rather than scaling them to simplified MRS analysis.

\subsection{Drift Limits}

The 1993 ECOL specifies the drift limit not to exceed $0.005 h_{s}$ in which $h_{s}$ is the interstorey height. The drift limit is increased in the later editions of the ECOL and is related to the existence and type of nonstructural elements as unreinforced masonry infills and the degree of importance of the building. Thus $d_{r} / v \leq 0.005 h$ or $0.0075 h$ or $0.01 h$ for buildings with brittle non-structural elements attached to the structure, with ductile non structural elements and with non-structural elements fixed in a way so as not to interfere with the structure, $h$ is the storey height. The displacement reduction factor $(v)$ is assigned to be either 2.5 for buildings with the two higher degree of importance and 2.0 for buildings with the last two lower importance.

In closure of overviewing the significant changes between the different editions of the ECOL, and to facilitate the comparison between the 2003 and 2008 $E C O L$ editions, the major changes of seismic provisions in these two editions are summarized in Table 2.

Table 2: Significant variations between 2003 and 2008 ECOL editions

\begin{tabular}{|l|l|}
\hline Item & Description \\
\hline Elastic design & $\begin{array}{l}\text { A reduction factors of } 1.4 \text { and } 1.28 \text { are to be applied to the forces } \\
\text { obtained using either } 2008 \text { or } 2003 \text { editions, respectively to be used in } \\
\text { elastic design. }\end{array}$ \\
\hline Seismic zones & $\begin{array}{l}\text { A new zone with } a_{g}=0.3 \mathrm{~g} \text { is appended in } 2008 \text { edition, changes in } \\
\text { seismic zones occurred to some cities. }\end{array}$ \\
\hline Effective ineria & $\begin{array}{l}I_{\text {eff }}=0.7 \text { for uncracked SW and } 0.5 \text { for cracked SW in } 2008 \text { edition, } \\
\text { while this value was fixed to } 0.35 \text { in } 2003 \text { edition. }\end{array}$ \\
\hline Live loads & A factor of 0.25 is newly assigned to the live load of dwellings. \\
\hline Period equations & $\begin{array}{l}\text { The second alternative to calculate period in } 2003 \text { edition for SW } \\
\text { buildings is omitted, Fundamental period calculated using spatial modal } \\
\text { not to exceed that is calculated using } 0.05 H^{3 / 4} \text { in } 2008 \text { edition. }\end{array}$ \\
\hline
\end{tabular}




\section{SEISMIC PROTECTION LEVEL IN VARIANT CODE EDITIONS}

The impact of changing the seismic provisions due to the evolution in ECOL from 1993 to 2008 on the degree of seismic protection level is investigated. The seismic protection level is simply expressed in terms of normalized base shear $(V / W)$, noting that it could be affected by other aspects of design and construction. For the purpose of comparing the provisions of different code editions, the normalized base shear is calculated utilizing the ESL method. A set of different parameters are considered in this comparative investigation as seismic zone, structural resisting system, code provided period equations, site soil conditions, importance factor and ductility level. The results of this investigation are illustrated in this section, noting that this investigation is carried out in the basis of ultimate loads, so the results obtained from the 1993 ECOL editions are multiplied by a factor of 1.28 .

Three different cities are selected to illustrate the impact of the geographic site seismic zone. These cities, arranged in the order of increasing the seismic zone effect, are Assiut, Cairo and Hurghada. The selection of these cities arises as they represent, according to either 2003 or 2008 ECOL editions, cities with low seismicity (Assiut; $a_{g}=0.1 \mathrm{~g}$ ), medium seismicity (Cairo; $a_{g}=0.15 \mathrm{~g}$ ) and high seismicity (Hurghada; $a_{g}=0.25 \mathrm{~g}$ ). Type 1 spectrum is the one specified by code to be used for the three selected cities. Relying on the 1993 ECOL edition, Assiut and Cairo were located in seismic zone II with $Z=0.2$ while Hurghada was located in seismic zone III with $Z=0.3$. The first investigated buildings are assumed to be ordinary types with importance factor equal 1.0. The reference soil type $\mathrm{C}$ is assigned to Assiut and Cairo while soil type B is assigned to Hurghada. The results of $(V / W)$ obtained for two commonly used types of RC structures, MRF and dual SW-MRF regular buildings, are illustrated in Figs. 3 and 4, respectively with horizontal axis represents the building height. The maximum considered building heights, $31.5 \mathrm{~m}$ for MRF and $52.5 \mathrm{~m}$ for SW-MRF buildings, are used so as to match the 2003 and 2008 ECOL restrictions of utilizing the simplified MRS method to buildings having fundamental period less than $4 T_{c}$ which is $1.0 \mathrm{sec}$. The three cities Assiut, Cairo and Hurghada are assigned the following notations ASS, CAR and HUR, respectively.

Discussing first the results obtained for the MRF buildings, it is clear, as shown in Fig. 3, that the seismic protection level SPL utilizing the 2008 ECOL edition is generally higher than that is obtained using the 1993 ECOL edition with different percentage changes. The minimum change is obtained for ASS city due to two reasons, the first one is the downgrading of the seismicity of this city from zone 2 (out of 3 zones) in 1993 edition to zone 1 (out of 6 zones) in 2008 edition. The second reason is due to the new low seismicity of this city. Generally, the \% change almost decreases as the building height increases. The observed \% change in seismic protection level for this city, due to changing the seismic provisions, ranges, over different building heights, between $22 \%$ and $43 \%$. As the site seismic intensity increases, the \% change in SPL increases. Although the degree of seismicity of the other two cities, Cairo and Hurghada, are not changed in the different code editions, the \% change in SPL drastically increases as the site seismicity increases. While this ratio of change ranges between $84 \%$ and $115 \%$ for CAR city it highly increases to range between $118 \%$ and $147 \%$ for HUR city, noting that the site seismicity is almost the same for the two 2003 
and 2008 code editions. It is worth to mention that the sudden change in the curves representing base shear is attributed to the correction factor $\lambda$.

In order to calculate the normalized base shear $V / W$ for the SW-MRF buildings as shown in Fig. 4, the width of the buildings, to be used in the 1993 ECOL period equation is assumed to be equal to $20 \mathrm{~m}$. The period equation $\left(T=0.05 \mathrm{H}^{3 / 4}\right)$ is used for calculating $V / W$ using the later code editions. It is observed that the \% change in the SPL in case of SW-MRF buildings is relatively less than what is observed for the MRF buildings by a ratio up to about $35 \%$, However, there is still extreme change in the results obtained using either 2003 or 2008 editions relative to the results obtained utilizing the 1993 edition. The new \% change in the SPL is in the range of $2 \%$ to $28 \%$ for ASS, $53 \%$ to $92 \%$ for CAR and $82 \%$ to $121 \%$ for HUR over the considered height.



Fig. 3 : Normalized base shear calculated for different cities (MRF building)



Building height (m)

Fig. 4: Normalized base shear calculated for different cities (SW-MRF building) 
The impact of changing the code equations to calculate the fundamental period of SW-MRF buildings in 1993 and 2003 editions is investigated. The impact of the variation in these equations could be better discussed through studying the SPL provided for a coastal city that relies to spectrum type 2 as Alexandria. The reason for this selections is that the second alternative of the 2003 ECOL edition for calculating the period for SW buildings, Eqs. 4 and 5 in this paper, yields high period values which require higher period limit to apply the simplified MRS method. The value of $T_{c}$ in spectrum type 2 yields an increase in the the validity of applying the simplified MRS method to values of $T$ ranges between 1.6 and $3.2 \mathrm{sec}$ for soil types arranged from A to D. In either 2003 or 2008 editions, Alexandria city is classified in seismic zone II (out of 6 zones) with $a_{g}=0.125 \mathrm{~g}$, while it was classified in zone III (out of 3 zones) in 1993 edition. The period equation in 1993 edition is affected by the width of building, so three different values for the building width B are investigated which are 10, 20 and $30 \mathrm{~m}$. The 2003 edition assigns the nominator $\left(r=L_{w} / H\right)$ to the period equation assigned to SW buildings, values of $r=0.3$ and 0.4 are considered for this type of soil, so that the resulting period rely to the code limitations of using simplified MRS. Firstly, discussing the effect of equation parameters, it can be observed, as shown in Fig. 5 that the values of seismic protection level increases with increasing either $B$ or $r$ when utilizing 1993 and 2003 ECOL editions, respectively. The maximum \% change in $V / W$ due to changing $B$, in reference to $20 \mathrm{~m}$ width, is $+11.1 \%$ and $-15.9 \%$ for $B=30$ and 20 $\mathrm{m}$, respectively. The variation in $r$ ratio from 0.3 to 0.4 results in $\%$ change of about $24 \%$. The impact of changing the whole period equation in the different code editions is well realized from the results obtained from 2003 and 2008 editions while all other parameters affecting the calculated base shear are identical in these two versions. There is extreme variation in the results obtained using these two versions, the $\%$ change is in a range between $50.9 \%$ to $102.4 \%$.

Comparing between the results obtained using 1993 and 2008 editions, noting that the results are affected by parameters other than period, it is found that the $\%$ change in SPL is in range of $-19.9 \%$ to $+56.5 \%$ depending on the building height.

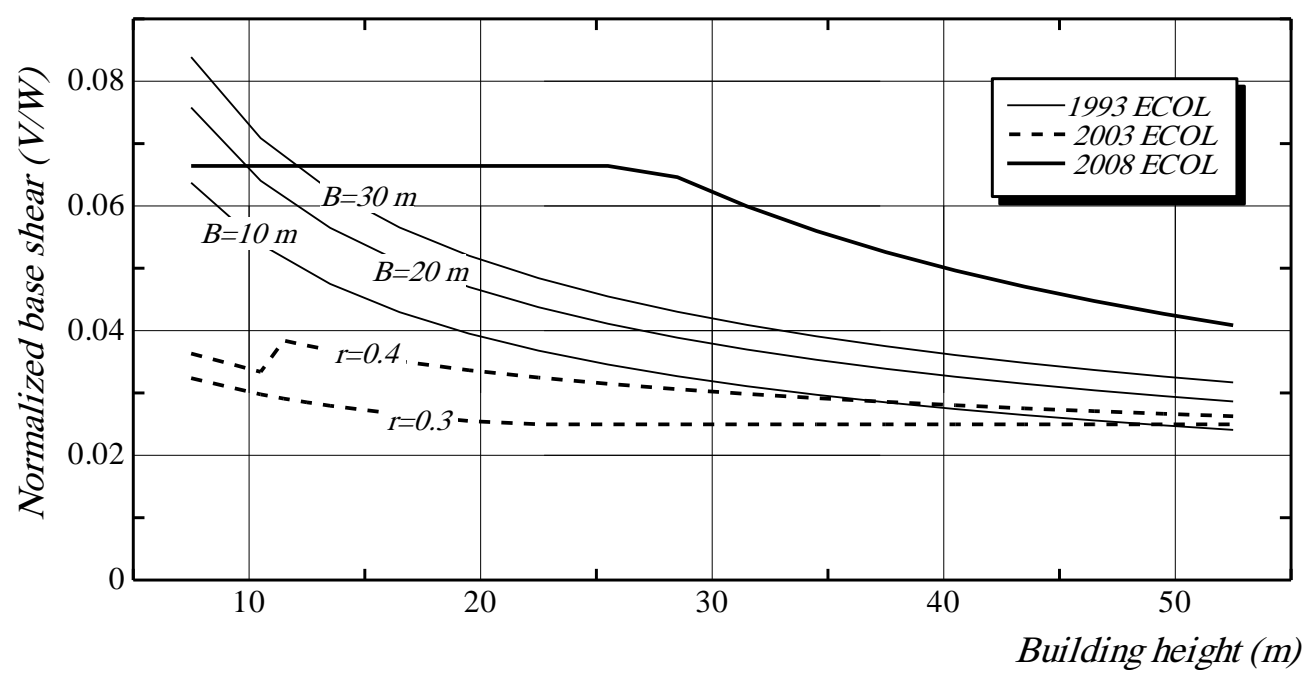

Fig. 5 : Effect of different period equations on the normalized base shear (Alex. City) 
It is mandatory, as mentioned before, in either 2003 or 2008 ECOL editions to carry out soil experiments to determine specifically the site subsoil type for buildings with high importance or located in high seismic zone. The soil type is determined according to actual records of shear wave velocity for a depth of at least $30 \mathrm{~m}$, if not available the penetration test could be carried out. The impact of soil is investigated for high importance buildings located in Cairo and found on different soil types relying on both 1993 and 2008 ECOL editions as illustrated in Fig. 6.

The soil type has a minor effect on the SPL in 1993 ECOL edition as its effect is directly influencing the base shear equation by a factor of $1,1.15$ or 1.3 for the different soil types. So, the \% change in the $V / W$, related to reference soil with $S=1.15$, does not exceed $\pm 13 \%$. In the later code editions, the subsoil condition affects the construction of the response spectrum and hence a high variation in the results and over height occurs. In more details and relating the results to the reference soil type $\mathrm{C}$, it is found that unlike soil type B which results in values close to those obtained for subsoil type with maximum $\%$ change does not exceed $10 \%$ there is extreme variation in results for the other two subsoil types. The \% change in $V / W$ could reach up to +44 and $-33 \%$ for subsoil types A and D, respectively.

Carrying out a comparison between the seismic protection level obtained utilizing the provisions of 1993 and 2008 ECOL editions, it is observed that the magnification of soil increases as the soil flexibility increases. While the \% change in seismic protection level ranges between $41 \%$ to $102 \%$ for buildings found on rock soil, it largely increases to reach a range of about $115 \%$ to $166 \%$ for buildings found on loose to medium cohesion subsoil.

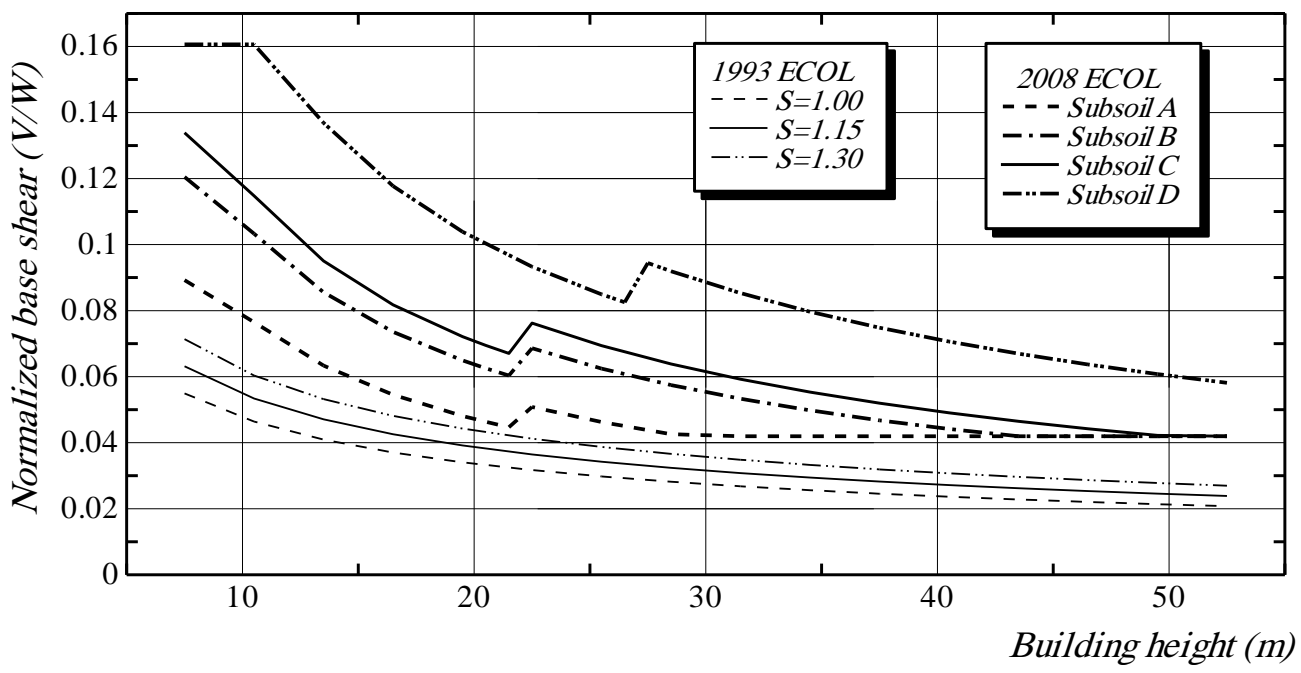

Fig. 6 : Effect of site soil conditions on normalized base shear (Cairo city)

A building presumed degree of importance plays a crucial role in determining the design base shear and hence the seismic protection level. A comparison between the values of normalized base shear for SW-MRF buildings located in Cairo city and having different degrees of importance assigned by the considered editions of the 
$E C O L$ is carried out. The purpose of this comparison is to evaluate the effect of changing the values of importance factor between the 1993 ECOL and the two subsequent editions. The results are shown in Fig. 7, in this figure the importance factor is assigned an annotation $I F$. It is found that the highest \% change in the SPL obtained from the 1993 edition and either of the two subsequent ones ranges between $81 \%$ and $130 \%$ is observed for buildings as schools, assembly halls, cultural institutes, tanks, silos and worship residences. The existence of seismic resistance is important for these buildings as their collapse cause casualty losses. The reason for this high change is attributed to that for these buildings, an innovated importance factor value of 1.2 is presented in either 2003 or 2008 ECOL while these buildings were treated as ordinary buildings with importance factor of 1.0 in 1993 ECOL. The \% change in the SPL between the 1993 and the two subsequent editions for buildings with vital importance is also high and ranges from $69 \%$ to $115 \%$. This ratio is higher than what was previously discussed for buildings with ordinary importance.

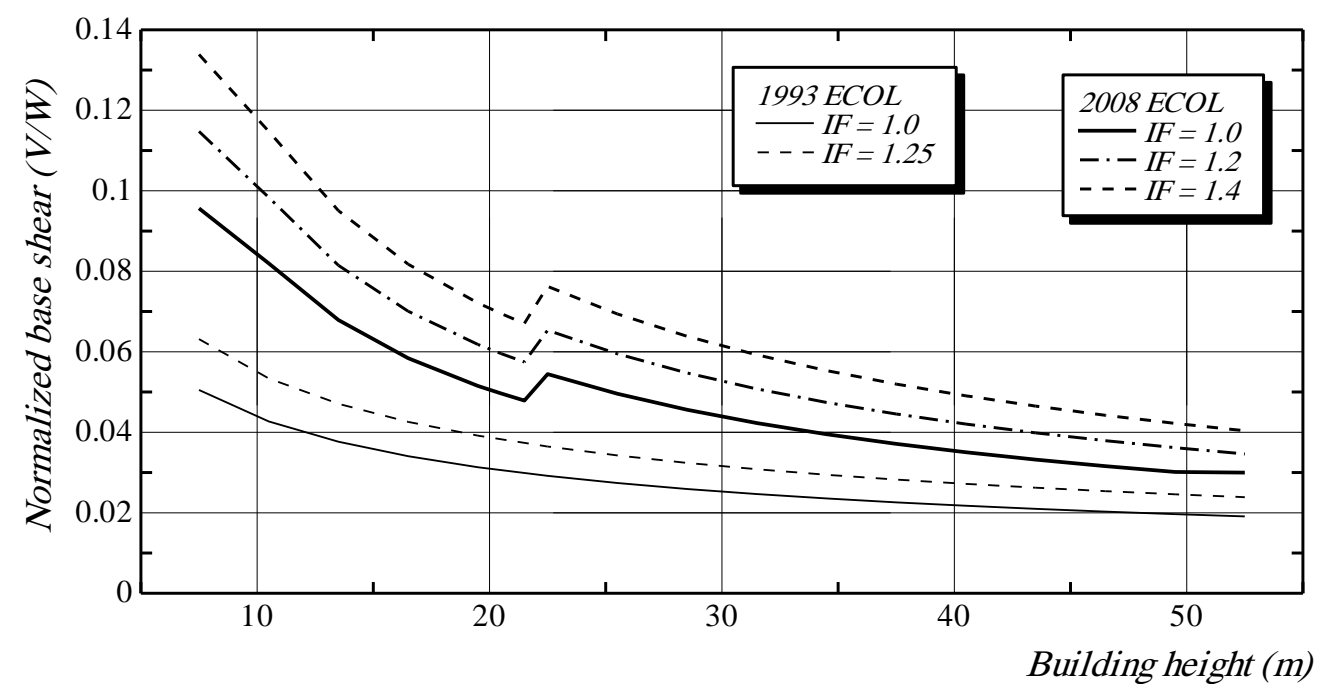

Fig. 7 : Effect of importance factor value on normalized base shear (Cairo city)

The effect of the variation in the building assigned ductility level between the different editions of the ECOL is also discussed for two types of buildings which are MRF and SW-MRF ones. These buildings are assumed to be located in Cairo city. Discussing first the results obtained for MRF buildings as shown in Fig. 8, it is found that the \% change in the SPL between 1993 and either of the two subsequent editions range between $44 \%$ and $128 \%$. This result is unlike the \% change which was observed for the non ductile or limited ductility buildings which ranged, as mentioned before, between $84 \%$ and $115 \%$. The wide range of variation in results for ductile buildings can be attributed to that the minimum value of base shear assigned by the $2008 \mathrm{ECOL}$ prevails the corresponding results of buildings from relatively low height till the end of the considered height. The domination of minimum base shear value also results in that the \% change in SPL for ductile buildings increases, generally, as building height increases. It is worth to mention here that unlike all the obtained curves for limited ductility buildings, the upward instantaneous change in the base shear results due to the 
correction factor, in Fig. 8 for height between 12.5 and $13.5 \mathrm{~m}$, is eliminated for ductile buildings.

The same comparison is carried out for SW-MRF buildings as shown in Fig. 9. The 1993 ECOL assigns a unique structural system factor of 1.0 for SW-MRF buildings regardless their ductility level. Two ductility levels are assigned for this type of buildings which are 5.0 and 6.0 for limited and sufficient ductility buildings, respectively in the later editions. So, the \% change in SPL for this type of buildings between the 1993 and the two subsequent ECOL editions is reduced in comparison with corresponding non ductile buildings and ranges between $37 \%$ and $60 \%$.



Fig. 8 : Effect of ductility level on normalized base shear (MRF building)

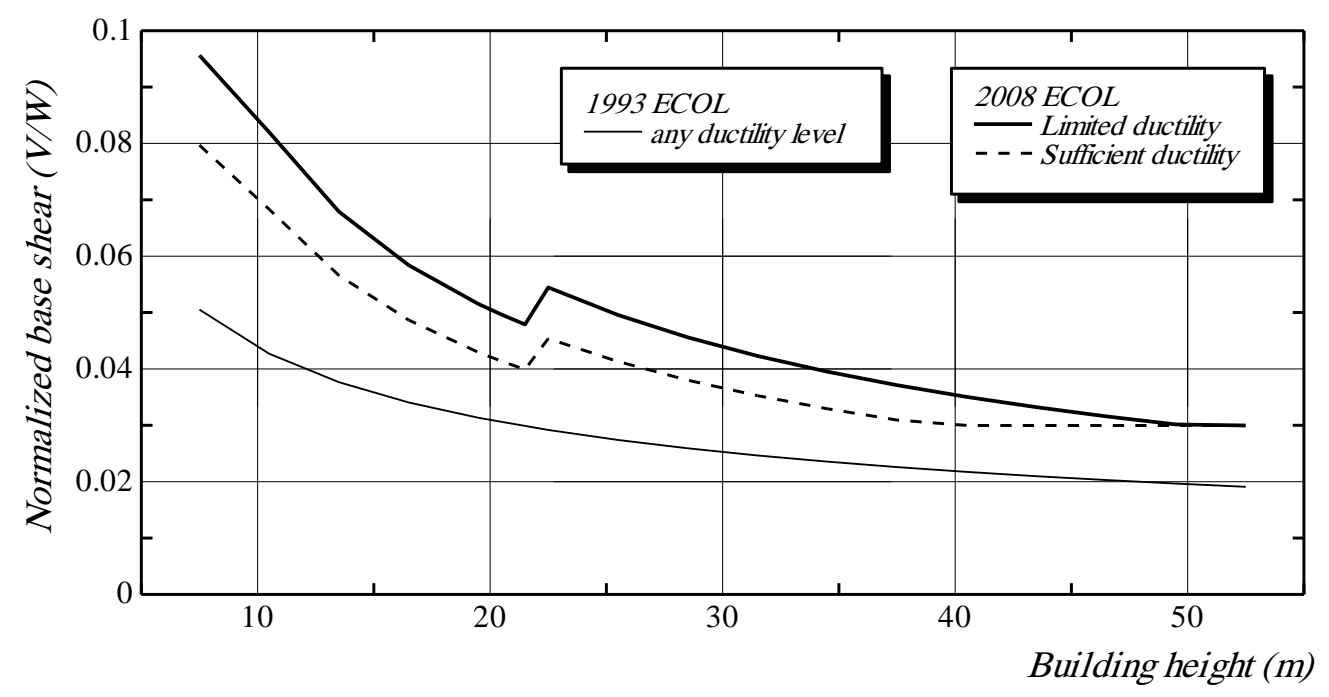

Fig. 9 : Effect of ductility level on normalized base shear (SW- MRF building) 


\section{CONCLUSIONS}

The significant changes in seismic provisions presented in different editions of the ECOL through years from 1993 to 2008 are briefly overviewed and discussed. An analytical investigation to evaluate the seismic protection level SPL of structures designed according to these code editions is carried out. The SPL is represented by the code calculated base shear relying on the simple modal response spectrum, called equivalent static load method in 1993 edition. Different building types over wide variety of heights are considered in this investigation. Relying on the investigations and discussions presented in this study, the following conclusions may be drawn out.

1) The major evolution in seismic provisions from 1993 ECOL to the later editions was remarked by the adoption of PGA depending response spectrum, adapted by factors to reflect the inelastic capacity of structures, instead of static approaches directly relating base shear to some parameters.

2) Changes in almost all seismic provision aspects are observed between 1993 ECOL edition and the latter ones. However, specific, yet influential, changes are remarkable between 2003 and 2008 editions.

3) While the equivalent static method was widely accepted by the earlier edition it now faces many restrictions leading, in many cases, to the mandatory application of either multi MRS or THA.

4) The applied changes between the 1993 edition and later ones have excessive impact on the SPL. Generally, for most studied cases with different parameters, the new 2008 code provisions yield higher SPL.

5) The \% change in normalized base shear between 1993 and 2008 editions increases as the site seismicity increases and usually decreases as the building height increases, this \% change could excessively reach values higher than $100 \%$.

6) The code provided equations to calculate the fundamental period of shear wall buildings play crucial role in the provided SPL. An evident example of non rational low SPL was provided by the second alternative period equation in 2003 $E C O L$ for shear wall buildings.

7) Unlike the minor site soil effect provided by 1993 ECOL edition, this parameter has now a crucial effect on the SPL increases in the order of soil flexibility. The \% change in SPL for the studied case reached $166 \%$ for flexible soil.

8) The \% change in SPL between 1993 and the subsequent ECOL editions highly increases for buildings with important seismic resistance, for which an innovated importance factor of 1.2 is presented in 2008 edition. For these buildings the \% change could reach up to $130 \%$. Buildings with vital importance also experienced high $\%$ change in SPL up to $115 \%$.

9) Ductile MRF buildings yield \% change in SPL, from 1993 edition to the subsequent two editions, higher than what was observed for buildings with limited ductility. This result is reversed for SW-MRF buildings as the 1993 edition neglect the ductility level of this type of buildings.

10) In closure of these findings and with reference to the provisions of the new 2008 ECOL, it seems to be that the safety of low to medium height buildings located in medium and high seismic zones and designed according to the earlier 1993 ECOL edition sometimes need to be reconsidered. This attention is to be increased for buildings with important seismic resistance or with vital importance. 


\section{REFERENCES}

1- " The Egyptian Code for Calculation of Loads and Forces in Structural and Building Work" Housing and Building Research Center, Cairo, Egypt, 1993.

2- Naeim, F.: “ The Seismic Design Handbook" Structural Engineering Series, Nan Nostrand Reinhold, 1989.

3- " The Egyptian Code for Calculation of Loads and Forces in Structural and Building Work, ECOL 201 "Housing and Building Research Center, Cairo, Egypt, 2003.

4- Eurocode-8: "Design of Structures for Earthquake Resistance" The European Committee for Standardization, Final Draft, December 2003.

5- " The Egyptian Code for Calculation of Loads and Forces in Structural and Building Work, ECOL 201 "Housing and Building Research Center, Cairo, Egypt, September 2008.

6- Akkar, S., Bommer, J.: " Prediction of Elastic Displacement Response Spectra in Europe and the Middle East "Journal of Earthquake Engineering and Structural Dynamic, Vol. 36, pp. 1275-1301, 2007.

7- Adams, J., Atkinson, G.: " Development of Seismic Hazard Maps for the Proposed 2005 Edition of the National Building Code of Canada " Can. J. Civ. Eng., Vol. 30, pp. 255-271, 2003.

8- Heidebrecht, A.C.: " Overview of Seismic Provisions of the Proposed 2005 Edition of the National Building Code of Canada " Can. J. Civ. Eng., Vol. 30, pp. 241-254, 2003.

9- Tinawi, R.: "An Overview of Fifty Years of Development for the Canadian Seismic Building Code "EGYQUAKE 3, Third Egyptian Conference on Earthquake Engineering, Cairo, 2004.

10- Haroun, M.A., Abdel Salam, M.N., Ismail,A.M.: " Fundamental Natural Period of Earthquake Resistant RC Buildings with Shear Wall Systems" Eleventh International Colloquium on Structural and Geotechnical Engineering, Egypt, 2005.

11- Abo El-Wafa, W.M.: " Effect of Masonry Infill Walls on the Natural Period of Reinforced Concrete Buildings" Journal of Engineering Science, Assiut University, Vol. 37, No.1, pp.29-49, 2009.

12- Mwafy, A., Mahmoud, H.: "Performance of the Multi-Storey Structures Designed According to The Egyptian Provisions for Ductile Frame "Eleventh International Colloquium on Structural and Geotechnical Engineering, Egypt, 2005.

13-Megahed, A., Mahmoud, H.: " Performance of the Multi-Storey Structures Designed According to The Egyptian Provisions for Ductile Frame "Eleventh International Colloquium on Structural and Geotechnical Engineering, Egypt, 2005.

14- Abo El-Wafa, W.M.: “ Nonlinear Lateral Response of Masonry Infilled RC Buildings with Variable Parameter" Journal of Engineering Science, Assiut University, Vol. 37, No. 3, pp. 521-541, 2009.

15- Bommer, J., Pinho, R.: “ Adapting Earhthquake Actions in Eurocode 8 for Performance-based Seismic Design " Journal of Earthquake Engineering and Structural Dynamics, Vol. 35, pp. 39-55, 2005. 


\section{مستوي الحماية الززلزالية المقدم من الإصدارات المختلفة للكود المصري للأحمال}

لقد كان ظهور الإصدار الأخير من الكود المصري للأحمال في سبتمبر 2008 دافعا قويا

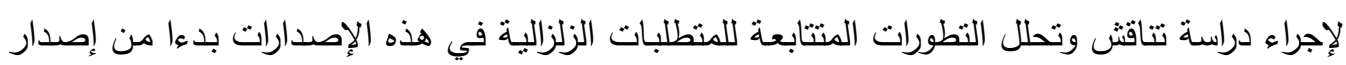

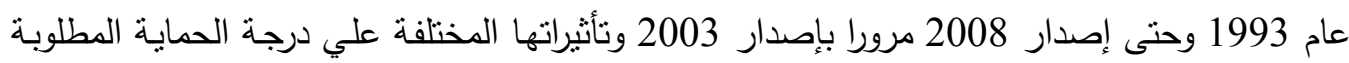
للمنشآت. ولتحقيق هذا الهدف فإنه بعد عرض ومناقشة أهم التغيرات التي طرأت علي المتغيرات الزلزالية

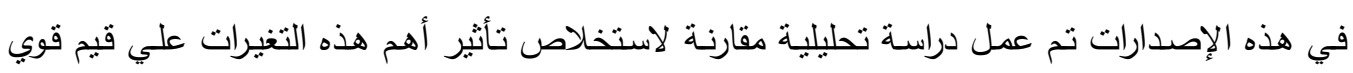



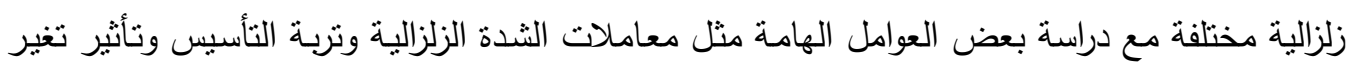

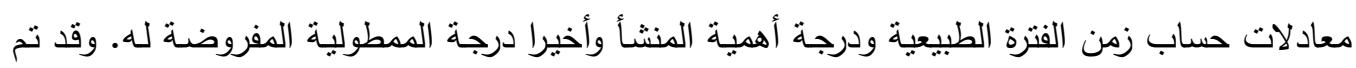



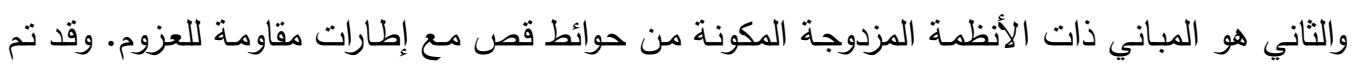

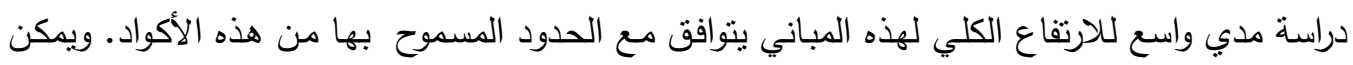
تلخيص النتائج التي نم الحصول عليها كالآتي: حدث تغيير جوهري ما بين إصداري 1993 و 2003 حيث اعتمد الأول علي الربط المباشر بين قوي القص وبعض العوامل بينما تبني الأخير طريقة طيف التجاوب المعتمدة علي العجلة الزلزالية

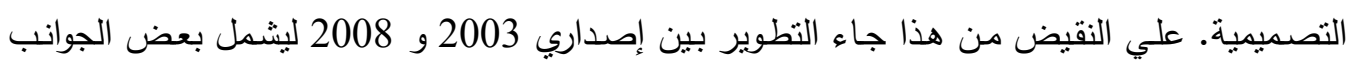

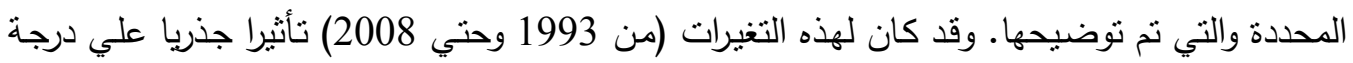
الحماية المقدمة للمنشأ. عموما, قد وجد أن قوي القص المحسوبة باستخدام الإصدار الأخير أعلي بكثير

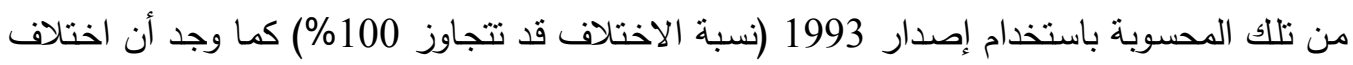

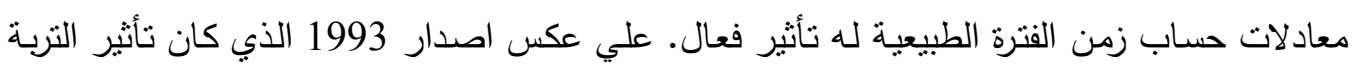

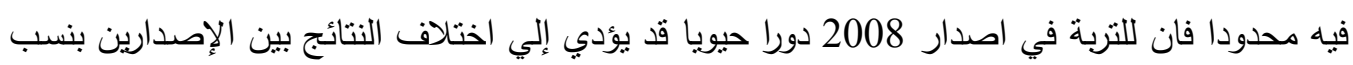

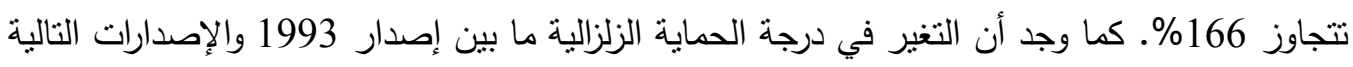

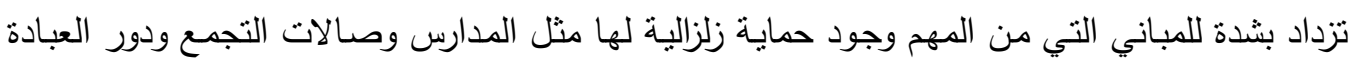


أن التغير في درجة الحماية الزلزالية يقل بالنسبة للمباني المطبلة ذات الإطارات المقاومة للعزوم مقارنة

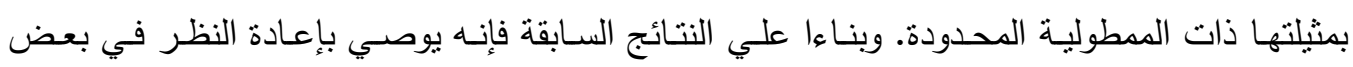

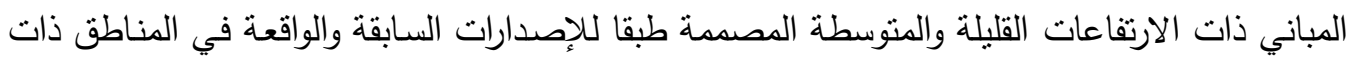

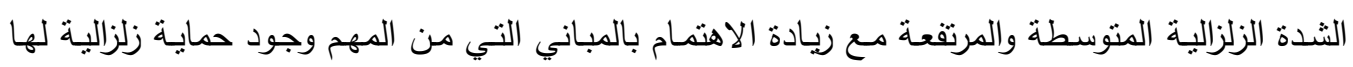
وكذلك المباني الحيوية. 